\title{
MENYEMAI AGEN PERUBAHAN KEBIJAKAN PUBLIK
}

\author{
Erna Irawati \\ Lembaga Administrasi Negara
}

\author{
Aldhino Niki Mancer \\ Lembaga Administrasi Negara
}

\begin{abstract}
Abstrak
Kebutuhan terhadap perbaikan kualitas kebijakan publik di Indonesia mendorong pemerintah membentuk Jabatan Fungsional Analis Kebijakan (JFAK) dan diformalkan melalui Peraturan Menteri Pendayagunaan Aparatur Negara dan Reformasi Birokrasi Nomor 45 Tahun 2013 (Permen PAN dan RB 45/2013) tentang Jabatan Fungsional Analis Kebijakan dan Angka Kreditnya. Dalam kurun waktu 3 tahun (2014-2016) menjalankan mandat sebagai instansi pembina JFAK, LAN menghadapi beberapa tantangan terkait implementasi PermenPAN dan RB 45/2013. Ada kebutuhan yang sangat tinggi terhadap Analis Kebijakan (AK) di Kementerian/Lembaga/Pemerintah Daerah (K/L/Pemda) namun, meski telah terseleksi sebanyak 150 Calon AK selama kurun waktu 3 tahun, baik melalui inpassing maupun pengangkatan pertama, hingga akhir tahun 2016 baru mencapai 50\% Calon AK yang telah diangkat oleh instansi pengusulnya. Ada beberapa pasal dalam PermenPAN dan RB 45/2013 yang masih dinilai menghambat pengembangan JFAK misalnya batas umur menjadi JFAK melalui inpassing dan perpindahan jabatan, persyaratan pendidikan, dan sebagainya. LAN perlu berkoordinasi dengan MenPAN dan RB untuk segera melakukan perbaikan terhadap beberapa pasal dalam Permen PAN dan RB 45/2013.
\end{abstract}

Kata kunci : kualitas kebijakan, analis kebijakan

\begin{abstract}
Policy Analyst position is established to respond the need for policy quality improvement in Indonesia. This position is regulated in Minister of State Apparatus Empowerment and Bureaucratic Reform Regulation No. 45 Year 2013 (Permen PAN dan RB 45/2013) concerning Functional Position of Policy Analyst and the Credit Point. During three years (2014-2016) development of this profession, NIPA has been facing challenges for implementing this regulation. Currently the need of policy analyst in Ministry/Agency/Local Government is difficult to reach. Among 150 policy analyst candidates that have been selected, through inpassing (position adjustment) and by first appointment, only about 50\% who has been formally appointed as policy analyst. Some articles of Permen PAN dan RB 45/2013 are considered hinder policy analyst development, i.e age limitation for position adjustment or transfer, education requirement, and so forth. NIPA in coordination with Ministry of State Apparatus Empowerment and Bureaucratic Reform are recommended to revise some articles of Permen PAN dan RB 45/2013.
\end{abstract}

Keywords : policy quality, policy analyst position 


\section{Latar Belakang}

JFAK dilahirkan atas dasar kebutuhan mendesak terhadap kerja nyata pemerintah dalam melakukan perbaikan kualitas kebijakan publik di Indonesia. Nugroho (2014) membangun premis bahwa keunggulan sebuah negara-bangsa ditentukan oleh keunggulan kebijakan publiknya yaitu kebijakan yang didukung oleh buktibukti (evidences) yang solid. LAN sebagai instansi pembina JFAK memiliki peran strategis dalam upaya membangun evidence-based policy making melalui ketersediaan Analis Kebijakan (AK) yang profesional. Untuk menjamin profesionalisme JFAK, proses seleksi AK dilakukan melalui uji kompetensi, baik yang dilakukan melalui proses inpassing untuk calon AK Ahli Madya, melalui perpindahan jabatan, maupun melalui pengangkatan pertama untuk calon $\mathrm{AK}$ Ahli Pertama.

LAN telah melakukan analisis Kebutuhan Formasi JFAK secara nasional untuk 5 (lima) tahun ke depan (2016-2020) dengan menggunakan perhitungan berdasarkan Peraturan Kepala LAN Nomor 32 Tahun 2014 tentang Pedoman Penyusunan Formasi JFAK. Analisis tersebut menghasilkan informasi bahwa dibutuhkan sekurangnya 6.000 (enam ribu) orang AK dari seluruh jenjang (jenjang ahli pertama sampai ahli utama) hingga tahun 2020. Namun dalam upaya mendorong pencapaian kuantitas $\mathrm{AK}$ yang ideal, LAN memiliki sejumlah tantangan yang dinilai cukup sulit karena terkait aturan yang telah ditetapkan dalam Permen PAN dan RB 45/2013. Beberapa ketentuan yang perlu diperbaiki misalnya batasan umur masuk ke dalam JFAK melalui inpassing dan perpindahan jabatan, persyaratan pendidikan doktoral untuk naik ke jenjang Ahli Utama, ketiadaan perpanjangan masa inpassing, dll.
Gambar 1: Eksisting data AK per

Oktober 2016

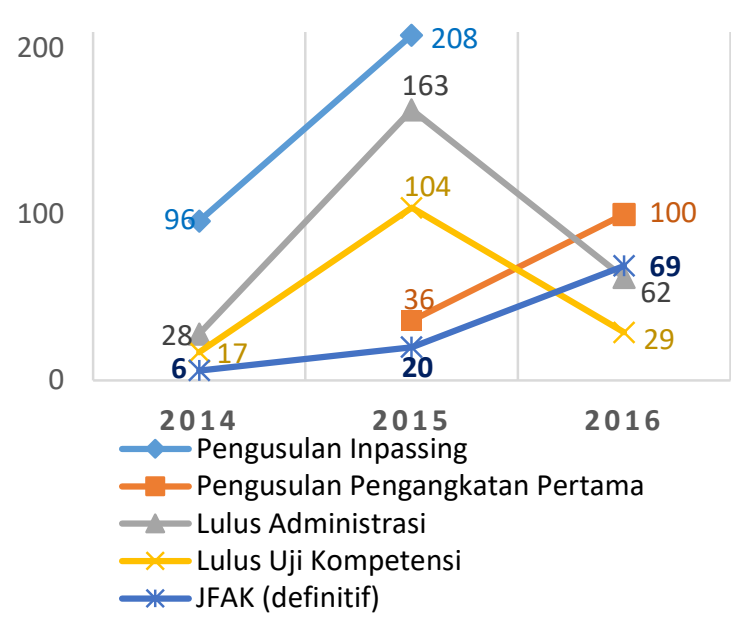

Sumber: PUSAKA LAN, 2016b (data diolah)

Gambar 1 di atas menunjukkan tingginya antusiasme terhadap JFAK yang dapat dilihat dari kecenderungan semakin banyaknya pengusulan untuk menjadi AK baik melalui inpassing maupun pengangkatan pertama sejak dimulainya seleksi JFAK pada Oktober 2014. Dalam kurun 3 tahun (2014-2016) ada 440 orang yang mengikuti seleksi JFAK dan sebanyak 253 orang lulus seleksi administrasi. Dari jumlah tersebut kemudian terpilih 150 orang yang direkomendasikan memenuhi kriteria untuk menjadi AK. Namun hingga Oktober 2016, baru diangkat sebanyak 77 pejabat fungsional Analis Kebijakan yang tersebar di beberapa $\mathrm{K} / \mathrm{L} / \mathrm{Pemda}$. Dari jumlah tersebut saat ini ada 8 (delapan) orang $\mathrm{AK}$ yang dibebaskan sementara karena menjadi struktural dan ada yang sedang menjalani tugas belajar sehingga, total AK yang aktif (definitif) per Oktober 2016 ada sebanyak 69 orang AK.

Gambaran sebaran AK di seluruh K/L/Pemda per Oktober 2016 yaitu: 


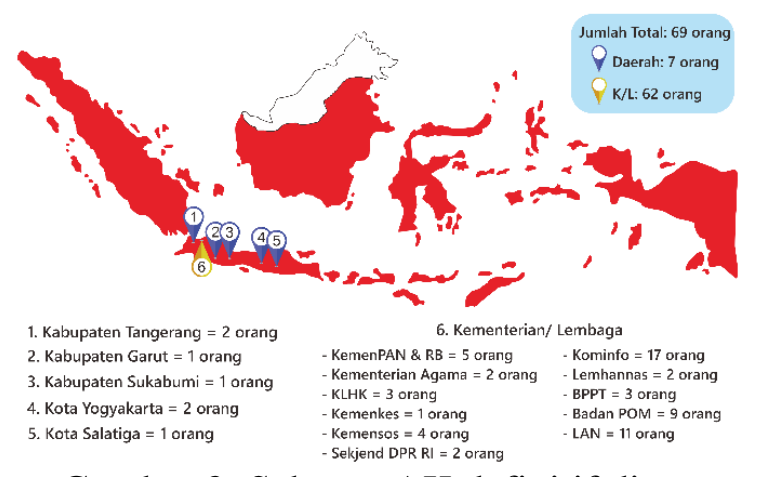

Gambar 2: Sebaran AK definitif di K/L/Pemda

Sumber: PUSAKA LAN, 2016b (data diolah)

Upaya meningkatkan kualitas kebijakan publik di Indonesia melalui peran Analis Kebijakan perlu menjadi komitmen bersama semua pihak. LAN terus berupaya meningkatkan jumlah AK agar mampu memenuhi formasi kebutuhan JFAK secara nasional. Data yang dimiliki PUSAKA LAN menunjukkan sebaran AK per Oktober 2016 masih sangat dominan berada di $\mathrm{K} / \mathrm{L}$ (Pusat) yaitu sebanyak $62 \mathrm{AK}$ (86\%) dan sisanya 7 AK (14\%) yang ada di Pemda. LAN sebagai instansi pembina JFAK mendorong agar dapat menurunkan gap antara realisasi kebutuhan terhadap AK secara nasional dengan kondisi AK seperti saat ini. Selain itu pula, LAN terus berupaya meningkatkan sebaran AK di daerah agar mampu melebihi jumlah AK yang ada di K/L.

Munculnya kebutuhan empiris untuk melakukan penataan kelembagaan organisasi perangkat daerah dengan diberlakukannya Peraturan Pemerintah Nomor 18 Tahun 2016 tentang Perangkat Daerah (PP 18/2016) menjadi momentum bagi JFAK untuk berkembang. Pejabat daerah yang terdampak perampingan dan memiliki pengalaman di area kebijakan dengan kompetensi yang memadai dapat masuk ke dalam JFAK.

\section{Perdebatan Kebijakan PerMEN PAN dan RB 45/2013}

Momentum dinamika kebijakan publik saat ini perlu didukung dengan kebijakan JFAK yang lebih akomodatif dan responsif terhadap kebutuhan pengembangan JFAK. Selain mendorong ASN menjadi AK, upaya perbaikan terhadap PermenPAN dan RB 45/2013 juga diarahkan untuk meningkatkan kualitas pembinaan AK. Terlebih lagi dengan telah ditetapkannya kelas jabatan JFAK oleh MenPAN dan RB diharapkan akan semakin menarik minat ASN dari seluruh K/L/Pemda untuk menjadi AK.

Tabel 1: Kelas Jabatan JFAK

\begin{tabular}{|c|l|c|}
\hline No. & Jenjang Jabatan & $\begin{array}{c}\text { Kelas } \\
\text { Jabatan }\end{array}$ \\
\hline $\mathbf{1}$ & $\mathbf{2}$ & $\mathbf{3}$ \\
\hline 1 & AK Ahli Pertama & 8 \\
\hline 2 & AK Ahli Muda & 10 \\
\hline 3 & AK Ahli Madya & 12 \\
\hline 4 & AK Ahli Utama & 14 \\
\hline
\end{tabular}

Sumber: Surat Edaran MenPAN dan RB No: B/2334/M.PANRB/6/2016 tanggal

27 Juni 2016 perihal Persetujuan Hasil Evaluasi JFAK

LAN telah mengidentifikasi poinpoin aturan dalam Permen PAN dan RB 45/2013 yang perlu direvisi. Catatancatatan perbaikan Permen PAN dan RB 45/2013 yang diusulkan antara lain:

1. Bab VIII tentang Pengangkatan dalam Jabatan, Pasal 25 ayat (2) dan (3) dan Pasal 26 ayat (1) poin (a) mensyaratkan akreditasi B perguruan tinggi asal Calon AK.

- Akreditasi pada satu sisi menjadi referensi terhadap standard pendidikan. Namun, KemenPAN dan RB tidak bisa memasukkannya sebagai persyaratan karena tidak ada rujukan hukum yang jelas dan kuat hingga saat ini. Persyaratan ini juga berpotensi merugikan lulusan dari perguruan tinggi di wilayah $3 \mathrm{~T}$ (terdepan, 
terluar, dan tertinggal) atau daerah-daerah yang belum maju pendidikannya. Implikasi lebih jauh dapat menutup pintu kesempatan bagi putera-puteri daerah yang berpotensi bagi daerahnya. Oleh sebab itu, persyaratan akreditasi perguruan tinggi ini tidak perlu dimasukkan dalam ketentuan PermenPAN dan RB tentang JFAK. Hal ini juga dimaksudkan untuk menyederhanakan aspek administratif dan lebih menekankan aspek substansi terkait dengan pengalaman kajian kebijakan dari calon AK yang diperoleh melalui hasil uji kompetensi. Di dalam uji kompetensi JFAK, pewawancara dapat mereview Daftar Riwayat Hidup (DRH) Calon AK sehingga dapat diketahui track record pengalaman kajian kebijakan, jejaring kerja (network) yang dimiliki, dll.

2. Bab VIII tentang Pengangkatan dalam Jabatan, Pasal 26 ayat (1) poin (g) mensyaratkan usia maksimal 50 tahun untuk dapat menjadi AK melalui jalur Perpindahan Jabatan dan sama seperti Bab XIV tentang Penyesuaian (Inpassing) dalam Jabatan dan Angka Kredit, Pasal 35 ayat (2) poin (f) mensyaratkan usia maksimal mengikuti inpassing adalah 50 tahun.

- PermenPAN dan RB tentang JFAK ini perlu melakukan penyesuaian kembali batasan usia maksimal masuk ke dalam JFAK. Penambahan batasan usia mengikuti perpindahan jabatan dan inpassing dimaksudkan untuk dapat mengakomodasi ASN yang pernah menduduki jabatan pimpinan tinggi (JPT) baik di pusat ataupun di daerah dan mereka tertarik masuk ke dalam JFAK setelah purna tugas dari
JPT. LAN mengusulkan batas usia 56 tahun sebagai batas usia maksimal untuk dapat masuk ke dalam JFAK baik melalui perpindahan jabatan maupun inpassing. ASN yang pernah menduduki JPT dianggap memiliki pengalaman dan kapasitas yang relevan dengan standar kompetensi JFAK. Hal tersebut akan dapat dibuktikan melalui proses uji kompetensi JFAK.

3. Bab XII tentang Kenaikan Pangkat/Jabatan, Pasal 30 ayat (3) mensyaratkan pendidikan S3 (Doktoral) untuk naik ke jenjang Ahli Utama.

- Persyaratan ini dalam implementasinya di K/L/daerah dinilai sangat menyulitkan dan kurang memenuhi prinsip keadilan, terutama kondisi akses pendidikan doktor di wilayah 3T (terdepan, terluar, dan tertinggal) atau daerah-daerah yang belum maju pendidikannya. Kondisi umur AK Madya yang sudah di atas 50 tahun pada sisi lain juga menjadi permasalahan tersendiri bagi yang ingin menempuh pendidikan S3. Terlebih lagi dengan adanya SE MenPAN dan RB No. 4 Tahun 2013 Tentang Pemberian Tugas Belajar dan Izin Belajar Bagi Pegawai Negeri Sipil yang mensyaratkan usia paling tinggi 40 tahun atau 47 tahun (bagi ASN dari wilayah 3T) untuk dapat menempuh pendidikan S3 dalam realitasnya sangat sulit dijumpai. Ketersediaan program pendidikan S3 pun tidak selalu tersedia di perguruan tinggi di daerah. Salah satu paradigma yang perlu dikembangkan ke depan di era UU ASN bahwa pengembangan kompetensi tidak selalu melalui pendidikan formal. Oleh sebab itu, ketentuan persyaratan pendidikan 
formal S3 dalam JFAK sebaiknya dihapuskan.

4. Bab XIII tentang Pembebasan Sementara dan Pengangkatan Kembali, Bagian Ke Satu tentang Pembebasan Sementara, Pasal 31 poin (d) tentang ketentuan pembebasan sementara dari JFAK karena ditugaskan secara penuh di luar JFAK.

- Klausul ini perlu diperjelas jenis penugasannya, khususnya terkait dengan penugasan ke dalam jabatan fungsional lain karena pertimbangan kepakaran dan uji kompetensi untuk mengecek kepakaran maka disarankan status yang bersangkutan tidak dibebaskan sementara tetapi diberhentikan dari JFAK.

5. Bab XIII tentang Pembebasan Sementara dan Pengangkatan Kembali, Bagian Kedua tentang Pengangkatan Kembali, Pasal 32 ayat (2) khususnya pada poin ketentuan tentang pengangkatan kembali ke dalam JFAK setelah menjalani cuti di luar tanggungan negara.

- Cuti di luar tanggungan negara didorong karena kebutuhan di luar tugas kedinasan dan dapat bersifat pribadi/individu. Kondisi tersebut memerlukan uji kompetensi ulang untuk memastikan komitmennya sebagai AK. Oleh sebab itu, ayat ini dapat diperjelas dengan penambahan klausul dapat diangkat kembali ke dalam JFAK apabila yang bersangkutan lulus uji kompetensi. Uji kompetensi perlu menjadi mekanisme pengangkatan kembali ke dalam JFAK bagi ASN yang telah selesai menjalani cuti di luar tanggungan negara.

6. Bab XIII tentang Pembebasan Sementara dan Pengangkatan Kembali, Bagian Kedua tentang Pengangkatan Kembali, Pasal 32 ayat (5) dan (6) mengatur pengangkatan kembali dalam jabatan Analis Kebijakan terkait kondisi: diberhentikan sementara sebagai ASN; menjalani cuti di luar tanggungan negara, kecuali untuk persalinan anak ke empat dan seterusnya; dan menjalani tugas belajar lebih dari 6 (enam) bulan. Kondisi-kondisi tersebut diatur lebih lanjut dalam Pasal 32 ayat (1), ayat (2), dan ayat (3), namun belum memberi ketentuan pengangkatan kembali yang disebutkan dalam pasal 32 ayat (4) yaitu tentang pengangkatan kembali atas kondisi ditugaskan secara penuh di luar jabatan AK.

- Perlu ditambahkan ketentuan yang mengatur pengangkatan kembali atas kondisi dalam Pasal 32 ayat (4) karena di dalam ayat baru sebatas disebutkan untuk kondisi ayat (1), (2), dan (3) yaitu kondisi: diberhentikan sementara sebagai ASN; menjalani cuti di luar tanggungan negara, kecuali untuk persalinan anak ke empat dan seterusnya; dan menjalani tugas belajar lebih dari 6 (enam) bulan, namun belum menyebutkan ketentuan atas kondisi ditugaskan secara penuh di luar jabatan AK.

7. Bab XIV tentang Penyesuaian (Inpassing) dalam Jabatan dan Angka Kredit, Pasal 35 ayat (6) tentang masa inpassing yang telah berakhir tahun 2015.

- Perpanjangan masa inpassing JFAK untuk memperluas kesempatan bagi Calon AK potensial yang berkompeten baik di pusat maupun di daerah dan tertarik menjadi AK. Terlebih bagi ASN yang pernah menduduki JPT Madya. Usulan ini sebagai alternatif jika MenPAN dan RB tidak menyelenggarakan inpassing 
nasional atau inpassing khusus JFAK.

8. Beberapa jenis satuan hasil dalam Lampiran PermenPAN RB kurang relevan.

- Penggunaan istilah "Ringkasan Kebijakan" dalam Lampiran I tentang Rincian Kegiatan dan Angka Kredit JFAK lebih tepat menggunakan istilah "Policy Brief'.

- Lampiran I, Sub Unsur (A) angka (4) belum menyebutkan "Naskah Akademik Rancangan Peraturan Pemerintah" dalam daftar satuan kegiatan yang dapat dinilai angka kreditnya dan perlu ditambahkan dalam PermenPAN dan RB tentang JFAK ini.

- Lampiran I, Sub Unsur (C) angka (3) menyebutkan "Surat Penugasan" sebagai satuan hasil kegiatan AK. Surat penugasan merupakan dokumen administratif, bukan sebagai satuan hasil kegiatan JFAK sehingga sebaiknya diganti dengan "Laporan konsultasi, dialog, dan diskusi (advokasi)".

9. Indikator kualitas hasil kegiatan $\mathrm{AK}$ yang disebutkan pada Pasal (7) dalam Peraturan Bersama Kepala LAN No. 16 Tahun 2014 dan Peraturan Kepala BKN No. 16 Tahun 2014 tentang Ketentuan Pelaksanaan PermenPAN dan RB No. 45 Tahun 2013, perlu dimasukkan ke dalam PermenPAN dan RB tentang JFAK dan Angka Kreditnya.

- Ketentuan ini sangat penting dan strategis terkait dengan penetapan standard kualitas satuan kegiatan AK sehingga dapat diakomodasi di dalam PermenPAN dan RB tentang JFAK dan Angka Kreditnya.

\section{Rekomendasi}

Dalam upaya meningkatkan sebaran JFAK secara nasional dan sebagai bentuk respon terhadap berbagai isu strategis yang muncul dalam dinamika kebijakan publik di Indonesia, LAN merekomendasikan perbaikan terhadap Permen PAN dan RB Nomor 45 Tahun 2013 tentang Jabatan Fungsional Analis Kebijakan dan Angka Kreditnya. LAN mengumpulkan masukan, saran, dan kritik dari para stakeholder sebagai bahan untuk perbaikan Permen PAN dan RB 45/2013. Arahnya adalah aturan yang memberi ruang yang lebih luas kepada ASN yang berkompeten di seluruh Indonesia untuk masuk ke dalam JFAK dan dapat berkontribusi secara berkelanjutan untuk membangun kebijakan publik di Indonesia menjadi lebih baik.

\section{Referensi}

\section{Buku}

Nugroho, Riant. 2014. Kebijakan Publik. Jakarta: Elex Media Computindo.

\section{Artikel}

PUSAKA LAN. 2016a. Laporan Utilisasi JFAK di Kementerian , Lembaga, dan Pemerintah Daerah. Jakarta: PUSAKA LAN. Dokumen dipublikasikan internal LAN. 2016b. Statistik JFAK. Data sistem informasi JFAK: www.jfak.lan.go.id

\section{Peraturan Perundangan}

Peraturan Menteri Pendayagunaan Aparatur Negara dan Reformasi Birokrasi Nomor 45 Tahun 2013 Jabatan Fungsional Analis Kebijakan dan Angka Kreditnya. 4 November 2013. Berita Negara Republik Indonesia Tahun 2013 Nomor 1342. Jakarta. 